\title{
Location and Characterization of Two Functions on RP1 That Inhibit the Fertility of the IncW Plasmid R388
}

\author{
By SHEIK T. FONG AND VILMA A. STANISICH* \\ Department of Microbiology, La Trobe University, Bundoora, 3083, Victoria, Australia
}

(Received 29 July 1988; accepted 16 November 1988)

\begin{abstract}
Two fertility-inhibition functions which reduce $\mathrm{R} 388$ (IncW) transfer were detected on RP1 $(60 \mathrm{~kb}, \mathrm{IncP})$. The respective genes, fiw $A$ and $f w B$, were mapped by transposon insertion mutagenesis to the regions between coordinates 32.8 to $31.7 \mathrm{~kb}(f i w A)$, and 59.8 to $0.8 \mathrm{~kb}$ ( fiwB). The $f i w A$ function occurs in a non-essential region of RP1 whereas $f w B$ is straddled by essential plasmid-maintenance and host-range determinants and apparently coincides (or overlaps) with the gene for tellurite-resistance.
\end{abstract}

\section{INTRODUCTION}

RP1 (IncP, $60 \mathrm{~kb}$ ) and two of its derivatives, pVS76 and pUB1601, are each capable of inhibiting the fertility of a co-resident R388 (IncW) plasmid (Yusoff \& Stanisich, 1984). pVS76 consists of the $6.0 \mathrm{~kb}$ Pst I fragment of RP1 inserted in the vector pBR322. This fragment is absent in pUB1601 $(49 \cdot 2 \mathrm{~kb})$, a ligation derivative of RP1 consisting of the two largest PstI fragments (Wallace et al., 1981). RP1 must, therefore, encode at least two fertility inhibition ( $f$ iw) functions, one of which affects only R388-transferability (the pVS76 component), while the other affects both R388-transferability and pilus production (the pUB1601 component) (Yusoff \& Stanisich, 1984). In this paper the position and phenotypic characteristics of the $f w$ determinants of pVS76 and pUB1601 are further defined.

\section{METHODS}

Bacteria. The Escherichia coli K12 sub-lines used were UB1301 (prototroph, Rif ${ }^{\mathrm{R}}$ ) (Grinsted et al., 1972), UB281 ( pro met $\mathrm{Nal}^{\mathrm{R}}$ ) (Hedges et al., 1973) and its recA56 derivative UB5201 (Sanchez et al., 1982), and various plasmidcarrying constructs of these bacteria. Pseudomonas aeruginosa PAO9505 (argB 18 chl-2 Rif ${ }^{\mathrm{R}}$ ) (Stanisich \& Bennett, 1976) lysogenized by a Tn504+ derivative of phage JA1 (Elliott, 1983) was also used.

Isolation of pVS76 fiw insertion mutants. Tn $501\left(\mathrm{Hg}^{\mathrm{R}}\right)$ insertion mutants of $\mathrm{pVS} 76$ were constructed by selecting for the conjugal conduction of pVS76 $\left(\mathrm{Tc}^{\mathrm{R}}\right)$ from an E. coli UB5201 sub-line carrying both pVS76 and a conjugallyproficient, $\mathrm{Tn} 501^{+}$derivative of $\mathrm{R} 388$. Selection was imposed for $\mathrm{Tc}^{\mathrm{R}}$ transconjugants, and those carrying $\mathrm{pVS} 76$ fiw::Tn501 insertion mutants were identified by their ability to re-transfer the co-resident R $388:: \operatorname{Tn} 501$ plasmid at high frequency. The putative pVS76 fiw plasmids were retrieved by transformation and retested to confirm their fiw phenotype.

Isolation of pUB 1601 fiw insertion mutants. A P. aeruginosa PAO9505 sub-line carrying pUB1601 $\left(\mathrm{Tc}^{\mathrm{R}} \mathrm{Km}^{\mathrm{R}} \mathrm{Tra}^{+}\right)$ and a chromosomally inserted $\mathrm{Tn} 504\left(\mathrm{Sm}^{\mathrm{R}}\right)$ was used as a conjugal donor to $E$. coli $\mathrm{UB} 5201(\mathrm{R} 388)$. The $\mathrm{Sm}^{\mathrm{R}}$ transconjugants obtained carried transpositional derivatives of pUB1601 and those with insertions in $f w$ were identified by their ability to transfer the co-resident R388 at high frequency. The putative pUB1601 fiw plasmids were retrieved by conjugational transfer and retested to confirm their fiw phenotype.

Isolation of pUB1601 Te $e^{\mathrm{R}}$ mutants. pUB1601 derivatives which express high-level resistance to tellurite were isolated by plating overnight broth cultures of E. coli UB1301(pUB1601) onto nutrient agar (Oxoid Blood Agar Base $3.5 \%, \mathrm{w} / \mathrm{v}$; Oxoid Yeast Extract $0 \cdot 5 \%$, w/v) supplemented with $\mathrm{K}_{2} \mathrm{TeO}_{3}\left(5 \mu \mathrm{g} \mathrm{ml} \mathrm{m}^{-1}\right.$; Sigma). The few resistant colonies that developed (about $10^{-6} \mathrm{ml}^{-1}$ ) were purified, the plasmid transferred by conjugation and the new sublines retested for expression of high-level tellurite resistance. Six mutants, each from independent cultures, were isolated. 
Recombinant DNA procedures. Digestion of DNA with restriction endonucleases, ligation of DNA, small-scale and large-scale plasmid preparations, agarose gel electrophoresis and transformation were carried out by standard procedures (Maniatis et al., 1982).

\section{RESULTS AND DISCUSSION}

\section{Localization and characterization of fiwA}

The $6.0 \mathrm{~kb} P_{s t} \mathrm{I}$ region of RP1, which carries a fiw determinant, has previously been cloned into the plasmid vector pBR322 to construct pVS76 (Fig. $1 b$; Yusoff \& Stanisich, 1984). Ten independently derived fiw mutants of pVS76 were obtained by Tn501 transposon mutagenesis (see Methods). Comparison of the restriction profiles of pVS76 and its derivatives revealed that all the latter carried Tn501 inserted in the $1.7 \mathrm{~kb} S s t \mathrm{II} / S m a \mathrm{I}$ fragment of RP1-derived DNA (Fig. $1 b$ ). The orientation and precise location of Tn501 in each derivative was determined relative to the asymmetrically placed SalI site within Tn501 (Fig. 1d) and the SstII and SalI sites within pVS76. Clustering of the Tn 501 insertions in the region $0.2-1.3 \mathrm{~kb}$ proximal to the Sst II site suggests a single fiw determinant, here designated fiwA, with the corresponding location between coordinates $32.8 \mathrm{~kb}$ to $31.7 \mathrm{~kb}$ on RP1. fiwA does not include the Sst II site at coordinate $33 \mathrm{~kb}$ since pVS517, a mutant of pVS76 deleted for the $1.5 \mathrm{~kb}$ SalI-Sst II fragment of RP1-derived DNA, retains fiwA activity. Whether or not fiwA includes the SmaI site at coordinate $31.3 \mathrm{~kb}$ has not been tested.

\section{Localization and characterization of fiwB}

Plasmid pUB1601, which consists of the two largest PstI fragments of RP1, carries a fiw determinant (Fig. 1 $a$; Yusoff \& Stanisich, 1984). Seven independently derived fiw mutants of pUB1601 were obtained by Tn504 transposon mutagenesis (see Methods). Comparison of the restriction profiles of pUB1601 and its derivatives showed that the latter consisted of two types. (i) pVS474, pVS475 and pVS480 were additive insertion mutants. The position and orientation of Tn504 in each mutant was determined from EcoRI/ApaI and PstI restriction profiles for pVS474, and EcoRI/SmaI and $K p n I / S m a I$ restriction profiles for $\mathrm{pVS} 475$ and pVS480. Insertion occurred $0.2 \mathrm{~kb}$ left of the EcoRI site (pVS474) or $0.5 \mathrm{~kb}$ right of this site (pVS475 and pVS480) (Fig. 1 c). (ii) pVS476 to pVS479 inclusive had sustained deletions associated with acquisition of Tn504. This was deduced from Eco RI/KpnI restriction profiles in which the $6.3 \mathrm{~kb}$ restriction fragment had increased in size, but not to the $11.5 \mathrm{~kb}$ expected from the addition of $\operatorname{Tn} 504$. The position of each deletion was determined (Fig. $1 \mathrm{c}$ ) and the smallest, of $0.6 \mathrm{~kb}$ in pVS478 and pVS479, extended from coordinate $0.8 \mathrm{~kb}$ across the $S m a I$ site at $0.9 \mathrm{~kb}$. These observations, together with those from the class (i) mutants suggests that a single fiw determinant, here

Table 1. Tellurite-resistance and fertility-inhibition phenotypes of plasmid-carrying derivatives of E. coli $\mathrm{K} I 2$

\begin{tabular}{lc}
\multicolumn{1}{c}{$\begin{array}{c}\text { IncP plasmid } \\
\text { carried }\end{array}$} & $\begin{array}{c}\text { MIC of } \\
\text { tellurite }\left(\mu \mathrm{g} \mathrm{ml}^{-1}\right)^{*}\end{array}$ \\
None & $0 \cdot 03$ \\
RP1 & $0 \cdot 3$ \\
pUB1601 & $0 \cdot 3$ \\
pUB1601 fiwB::Tn504 & $0 \cdot 03$ \\
pUB1601Te & $>5$
\end{tabular}

Transfer frequency
of $\mathrm{R} 388^{\dagger}$
1.2
$2.5 \times 10^{-5}$
$9 \cdot 0 \times 10^{-3}$
$9 \cdot 0 \times 10^{-1}$
$7.5 \times 10^{-2}$

* Nutrient agar was supplemented with $\mathrm{K}_{2} \mathrm{TeO}_{3}$ using $0 \cdot 01 \mu \mathrm{g} \mathrm{ml}^{-1}$ increments over the range $0 \cdot 01-0 \cdot 1 \mu \mathrm{g} \mathrm{ml}^{-1}$ and $0 \cdot 1 \mu \mathrm{g} \mathrm{ml}^{-1}$ increments over the range $0 \cdot 1-1 \mu \mathrm{g} \mathrm{ml}^{-1}$. Samples $(20 \mu \mathrm{l})$ of serially diluted overnight broth cultures of E. coli UB1301 and its IncP $\mathrm{P}^{+}$derivatives were spotted onto the supplemented plates. The MIC of tellurite was taken as the minimum concentration required to inhibit the growth of single colonies after $24-48 \mathrm{~h}$ incubation.

$\dagger$ Spot plate matings were carried out in which $20 \mu \mathrm{l}$ of serial dilutions of the donor cultures (UB1301 derivatives carrying R388 alone or together with an IncP plasmid) were inoculated onto the surface of selective medium previously seeded with UB281. R388+ transconjugants were isolated on Oxoid DST Agar supplemented with nalidixic acid $\left(10 \mu \mathrm{g} \mathrm{ml}^{-1}\right)$ and trimethoprim $\left(1 \mu \mathrm{g} \mathrm{ml}^{-1}\right)$. The data presented for the pUB1601 mutants are representative of those obtained for the seven fiw $B:: \mathrm{Tn} 504$ mutants (range $\left.=6.5 \times 10^{-1}-1 \cdot 2\right)$ and the six $\mathrm{Te}^{\mathrm{R}}$ mutants $\left(\right.$ range $=6.0 \times 10^{-2}-1.0 \times 10^{-1}$ ). 

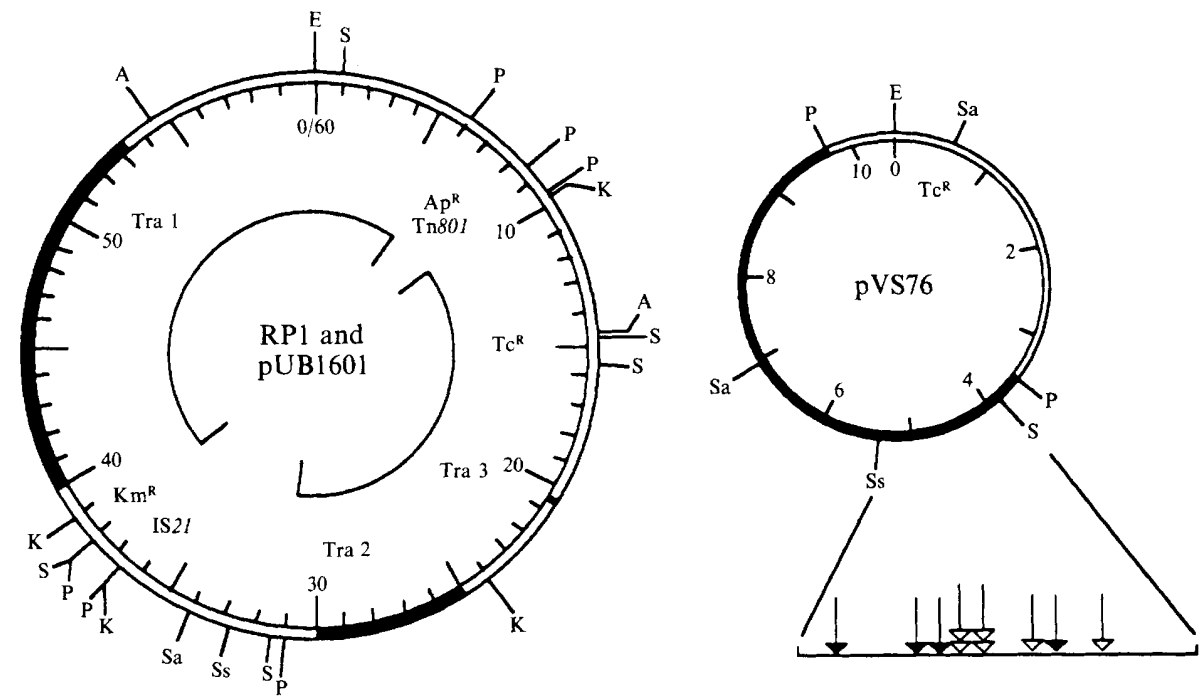

(a)

(b)
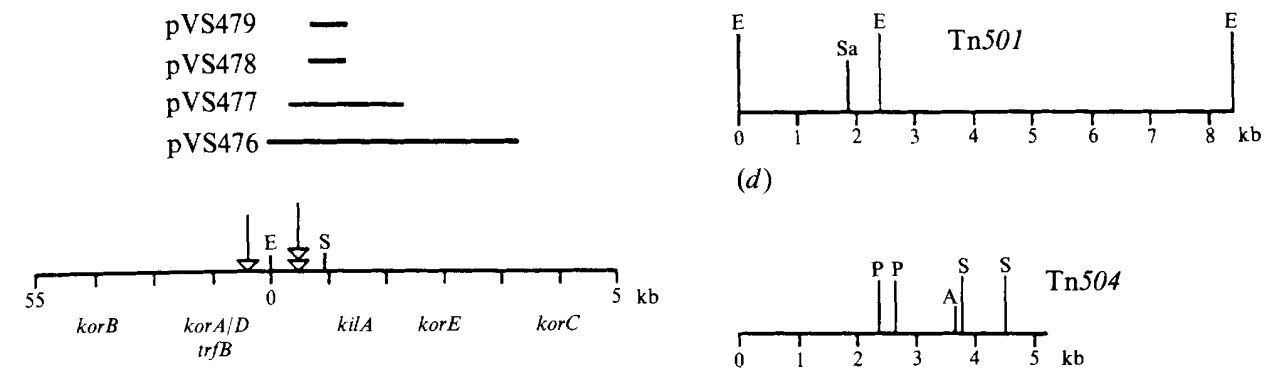

(d)

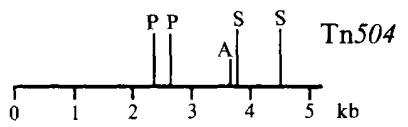

(c)

(e)

Fig. 1. (a) The map of RP1 (60 kb) (outer circle) is based on that of Thomas \& Smith (1987). The positions of the transfer (Tra) regions, resistance functions and transposable elements ( $\mathrm{Tn} 801 \mathrm{Ap}^{\mathrm{R}}$ and IS21) are indicated. Plasmid pUB1601 (49.2 kb) (inner circle) is a ligation derivative of RP1 consisting of the two largest Pst I fragments (Wallace et al., 1981). (b) Plasmid pVS76 (10.4 kb) is a PstI ligation derivative of pBR322 (light region) and the $6 \mathrm{~kb}$ PstI fragment of RP1 (dark region). The locations of Tn 501 in the various pVS76::Tn501 derivatives are shown by arrowheads in the linearized extension. (c) A linearized expansion of the $55 \mathrm{~kb}$ to $5 \mathrm{~kb}$ region of RP1, with the positions of plasmidmaintenance and host-range determinants ( $k i l$, kor and $\operatorname{tr} f$ loci) shown. Arrowheads mark the position of $\mathrm{Tn} 504$, and the bars above the map indicate the extent of deletions associated with the inheritance of this transposon by various pUB1601::Tn504 derivatives. (d) The simplified map of $\mathrm{Tn} 501\left(\mathrm{Hg}^{\mathrm{R}}\right)$ $(8.2 \mathrm{~kb})$ is based on that of Bennett et al. (1978). (e) The map of $\operatorname{Tn} 504\left(\mathrm{Sm}^{\mathrm{R}}\right)(5.2 \mathrm{~kb})$ is shown. This transposon was detected on plasmid pVS5 (IncP2) carried by a clinical Pseudomonas aeruginosa strain from Germany (Arwas, 1982) and resembles Tn904 (McCombie et al. 1983). In (b) and (c) open arrowheads represent transposon insertions in the orientation shown on the maps in $(d)$ and $(e)$; filled arrowheads represent the opposite orientation. In all figures cleavage sites for various restriction enzymes are as follows: Pst I (P), SmaI (S), ApaI (A), KpnI (K), EcoRI (E), Sst II (Ss), SalI (Sa). In the case of RP1, only the SstII and Sall sites that occur in the $6.0 \mathrm{~kb}$ PstI fragment are shown.

designated $f i w B$, occurs in pUB 1601 in the region $0.2 \mathrm{~kb}$ left of the $E c o$ RI site to at least $0.8 \mathrm{~kb}$ right of this site. This determinant may, in addition, include the $S m a$ I site at $0.9 \mathrm{~kb}$.

The location of $f w B$ in the EcoRI $(59.8-0.8 \mathrm{~kb})$ region of RP1 is unexpected since it coincides (or overlaps) with that of the tellurite-resistance $\left(\mathrm{Te}^{\mathrm{R}}\right)$ determinant. The latter has been mapped in the apparently identical plasmid RP4 (Thomas \& Smith, 1987) and just spans the EcoRI $(0 \mathrm{~kb})$ and $S m a \mathrm{I}(0.9 \mathrm{~kb})$ sites (Taylor \& Bradley, 1987). Te ${ }^{\mathrm{R}}$ function is normally 'silent', unlike 
that of $f w B$, and is confined to IncP $\alpha$ plasmids (Bradley, 1985; Taylor \& Bradley, 1987). Members of the IncP $\beta$ group carry neither Te ${ }^{R}$ (i.e. R751 and R772; Bradley, 1985) nor fiwB (i.e. R751 and R906; Yusoff \& Stanisich, 1984). We examined the possible relationship between the $\mathrm{Te}^{\mathrm{R}}$ and $f w B$ functions of RP1 by testing plasmids which exhibited one of these functions for the alternative property (Table 1). Contrary to previous descriptions of RP4 (Summers \& Jacoby, 1977; Bradley, 1985; Taylor \& Bradley, 1987), both RP1 and pUB1601 conferred constitutive resistance to tellurite, albeit at a low level (MIC $0.3 \mu \mathrm{g} \mathrm{ml}^{-1}$; Table 1). This resistance was reduced to the host level $\left(0.03 \mu \mathrm{g} \mathrm{ml}^{-1}\right)$ in all sub-lines carrying pUB1601 fiwB::Tn504 mutants. Thus in pUB1601 $\left(f w B^{+}\right)$, and presumably also in RP1 $\left(f w A^{+} f i w B^{+}\right)$, the expression of $f w B$ correlates with that of low-level tellurite-resistance. In the converse situation, spontaneous mutants of pUB 1601 which exhibited high-level resistance to tellurite were found to be less effective than the parent $f w B^{+}$plasmid in inhibiting the fertility of $\mathbf{R} 388$. These various observations raise the possibility that tellurite-resistance and $f w B$-mediated fertility inhibition are effected by the same RP1 determinant or by two closely linked determinants with interacting effects. However, the mechanism(s) underlying these phenotypes remains to be determined.

Financial support for this work was provided by the Australian Research Grants Scheme.

\section{REFERENCES}

ARWAS, R. (1982). A study of transposons and transposon-mediated genetic interactions in Pseudomonas aeruginosa. PhD thesis, La Trobe University, Australia.

Bennett, P. M., Grinsted, J., Choi, C. L. \& RichmoND, M. H. (1978). Characterisation of Tn501, a transposon determining resistance to mercuric ions. Molecular and General Genetics 159, 101-106

BRadLEY, D. E. (1985). Detection of tellurite-resistance determinants in IncP plasmids. Journal of General Microbiology 131, 3135-3137.

ElliotT, S. (1983). Interactions of transposons Tn504 and Tn801 with DNA molecules in Pseudomonas aeruginosa $P A O$. MSc thesis, La Trobe University, Australia.

Grinsted, J., Saunders, J. R., Ingram, L. C., Sykes, R. B. \& Richmond, M. H. (1972). Properties of an R factor which originated in Pseudomonas aeruginosa 1822. Journal of Bacteriology 110, 529-537.

Hedges, R. W., DatTa, N., Coetzee, J. N. \& Dennison, S. (1973). R factors from Proteus morganii. Journal of General Microbiology 77, 249-259.

Maniatis, T., Fritsch, E. F. \& Sambrook, J. (1982). Molecular Cloning: a Laboratory Manual. Cold Spring Harbor, NY: Cold Spring Harbor Laboratory.

McCombie, W., Hansen, J. B., Zylstra, G. J., Maurer, B. \& Olsen, R. H. (1983). Pseudomonas streptomycin resistance transposon associated with
R-plasmid mobilization. Journal of Bacteriology 155 , 40-48.

Sanchez, J., Bennett, P. M. \& Richmond, M. H. (1982). Expression of elt $B$, the gene encoding the B sub-unit of the heat-labile enterotoxin of Escherichia coli, when cloned in PACYC184. FEMS Microbiology Letters 14, 1-5.

Stanisich, V. A. \& Bennett, P. M. (1976). The properties of hybrids formed between the P-group plasmid RP1 and various plasmids from Pseudomonas aeruginosa. Molecular and General Genetics 149, 217-223.

Summers, A. O. \& JACOBY, G. A. (1977). Plasmiddetermined resistance to tellurite compounds. Journal of Bacteriology 129, 276-281.

TAYLOR, D. E. \& BRADLEY, D. E. (1987). Location on RP4 of a tellurite resistance determinant not normally expressed in IncP $\alpha$ plasmids. Antimicrobial Agents and Chemotherapy 31, 823-825.

Thomas, C. M. \& SMIтH, C. A. (1987). Incompatibility group $\mathrm{P}$ plasmids: genetics, evolution, and use in genetic engineering. Annual Review of Microbiology 41, 77-101.

Wallace, L. J., WARD, J. M. \& Richmond, M. H. (1981). The location of sequences of TnA required for the establishment of transposition immunity. Molecular and General Genetics 184, 80-86.

YusofF, K. \& Stanisich, V. A. (1984). Location of a function on RP1 that fertility inhibits Inc W plasmids. Plasmid 11, 178-181. 